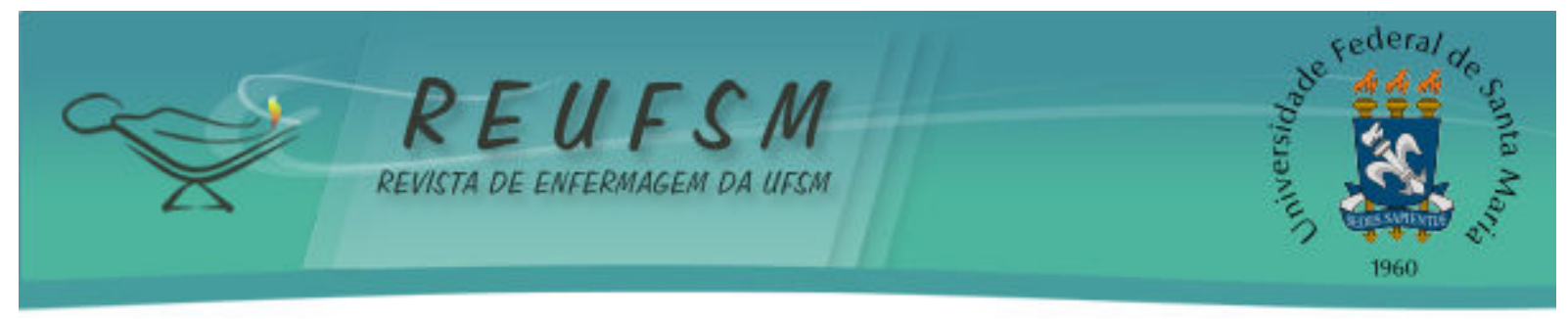

ARTIGO ORIGINAL

\title{
MOTIVOS E REPERCUSSÕES DA PARTICIPAÇÃO DE GESTANTES EM GRUPO OPERATIVO NO PRÉ-NATAL
}

\author{
REASONS AND REPERCUSSIONS OF PREGNANT WOMEN PARTICIPATION IN OPERATIVE \\ GROUP DURING PRENATAL CARE
}

\section{MOTIVOS Y REPERCUSIONES DE LA PARTICIPACIÓN DE MUJERES EMBARAZADAS EN GRUPO OPERATIVO PRENATAL}

\author{
Luana Carine Maron ${ }^{1}$ \\ Fernanda Beheregaray Cabral $^{2}$ \\ Isabel Cristina Pacheco Van der Sand ${ }^{3}$ \\ Leila Mariza Hildebrandt ${ }^{4}$
}

Doi: $10.5902 / 2179769210827$

RESUMO: Objetivos: conhecer as motivações de mulheres-mães e familiares para a participação em grupo operativo de gestantes e identificar a repercussão de sua participação nessa atividade. Método: trata-se de pesquisa qualitativa, descritiva, cujos sujeitos foram participantes de grupos operativos de gestantes em município do norte do Rio Grande do Sul/RS. Os dados foram coletados por meio de entrevista semiestruturada e submetidos à análise temática. Resultados: os motivos para participação em grupo de gestantes sintetizaram-se na pouca experiência e dificuldades em relação à maternidade e suas demandas. A participação no grupo emergiu como estratégia preparatória à maternidade, formação de amizades, ampliação das relações interpessoais, construção de redes sociais e mudança de hábitos de vida. Considerações finais: o grupo constituiu-se em espaço de diálogo, de troca de experiências e de reflexão sobre as ofertas de cuidado ao processo de nascimento.

Descritores: Enfermagem; Saúde da mulher; Educação em saúde; Prática de grupo; Cuidado pré-natal.

ABSTRACT: Aim: to identify the motivations of women-mothers and their relatives to join an operative group for pregnant women and the repercussions of their participation in this activity. Methods: it is a qualitative and descriptive research. The subjects of the study were selected among participants of operative groups in a city in the North of the state of Rio Grande do Sul, Brazil. The data were collected by semi-structured interviews and submitted to thematic analysis. Results: the reasons why the study subjects join an operative group can be summarized in little experience and difficulties related to maternity and its demands. The participation in the group emerged as a strategy to prepare for motherhood, make new friends, expand their interpersonal relations, build

\footnotetext{
1 Enfermeira, graduada pela Universidade Federal de Santa Maria/UFSM Centro de Educação Superior Norte do Estado do Rio Grande do Sul/CESNORS, Palmeira das Missões-RS. Especialista em Saúde do Trabalhador pela UNINTER Centro Universitário Internacional. Email: luana.maron12@hotmail.com Fone: (55)9965-2226.

2 Enfermeira Obstetra. Mestre em Enfermagem. Professora Assistente do Departamento de Ciências da Saúde do CESNORS/UFSM. Rio Grande do Sul, Brasil. E-mail:cabralfernandab@gmail.com

3 Enfermeira Obstetra. Mestre em Enfermagem. Professora Assistente do Departamento de Ciências da Saúde do CESNORS/UFSM. Rio Grande do Sul, Brasil. E-mail: isabelvan@gmail.com

Professora assistente do Departamento de Ciências da Saúde do CESNORS/UFSM. Rio Grande do Sul, Brasil. Email:leilahildebrandt@yahoo.com.br

4 Enfermeira. Mestre em Enfermagem. Professora Assistente do Departamento de Ciências da Saúde do CESNORS/UFSM. Rio Grande do Sul, Brasil. E-mail:leilahildebrandt@yahoo.com.br
} 




new social networks and make changes on lifestyle. Final considerations: the group consisted of a dialogue space, in which it was possible to exchange experiences and reflections on the care offer related to the birth process.

Descriptors: Nursing; Women's health; Health education; Group practice; Prenatal care.

RESUMEN: Objetivos: conocer las motivaciones de mujeres embarazadas y familiares para la participación en grupo operativo e identificar la repercusión de su participación en esta actividad. Método: investigación cualitativa, descriptiva, cuyos sujetos fueron participantes en grupo operativo de gestantes en municipio del norte del estado del Rio Grande do Sul - Brasil. Los datos fueron recolectados mediante encuesta semiestructurada y sometidos a análisis temático. Resultados: los motivos de la participación en grupo de gestantes se sintetizan en la poca experiencia y dificultades en relación a la maternidad y sus demandas. La participación en el grupo emergió como estrategia preparatoria a la maternidad, formación de amistades, ampliación de las relaciones interpersonales, construcción de redes sociales y cambio de hábitos de vida. Consideraciones finales: el grupo se constituye en espacio de dialogo, de intercambio de experiencias y de reflexión sobre las ofertas de cuidado al proceso de nacimiento.

Descriptores: EnfermeríaSalud de la mujer; Educación en salud; Práctica de grupo; Atención prenatal

\section{INTRODUÇÃO}

A gestação é uma condição especial do processo de saúde e caracteriza-se por um período de mudanças biopsicossociais, emocionais e culturais. Muitas vezes, essas transformações implicam na redefinição e adaptação a novos papéis sociais para a gestante - que nesse estudo será referida como mulher-mãe - e para seus familiares com seus medos, dúvidas, angústias, fantasias e expectativas sobre o que está por vir. ${ }^{1-3}$

A experiência de todo o processo de nascimento, desde o pré-natal até o puerpério, é vivenciada de acordo com a singularidade de cada mulher-mãe e de todos que estão implicados nesse processo, o que contribui para sua complexidade, sendo assim, destaca-se que essa etapa vivencial requer acompanhamento e apoio. 0 diálogo franco, a escuta, a produção de espaços para expressão de preocupações e sentimentos são ações que favorecem a promoção da saúde da mulher-mãe. ${ }^{1-2}$

As atividades de natureza grupal em saúde constituem-se peças fundamentais para suprir os anseios e necessidades dos indivíduos que precisam de suporte. Isso ocorre em função de o grupo ser um conjunto de pessoas unidas entre si, porque se colocam objetivos e/ou ideais em comum e se reconhecem interligadas por estes, o que, por conseguinte, resulta em suporte para cada um e a todos seus integrantes, fazendo do espaço grupal um lugar privilegiado de escuta e reflexão. ${ }^{4}$

Em específico, existem os grupos de gestantes, em que as trocas, comumente, referem-se às questões da parentalidade e aspectos do ciclo gravídico-puerperal. 0 processo grupal favorece, então, a tomada de consciência de que as experiências e as vivências compartilhadas entre os integrantes, ainda que subjetivas e individuais, podem ser comuns a muitos. Isso os identifica e os vincula, mobilizando-os para a realização de tarefas que os congrega para reunirem-se em grupo. ${ }^{4-5}$

Nessa perspectiva, destacam-se os grupos operativos, que são centrados na tarefa, fornecendo aos participantes, por meio da técnica operativa, a possibilidade de se darem conta e explorar suas fantasias básicas. Estes integrantes criam condições de mobilizar e romper suas estruturas estereotipadas, que são formas rígidas e cristalizadas de pensar sobre determinado assunto. Esse tipo de grupo é um dispositivo potente para o enfrentamento da 


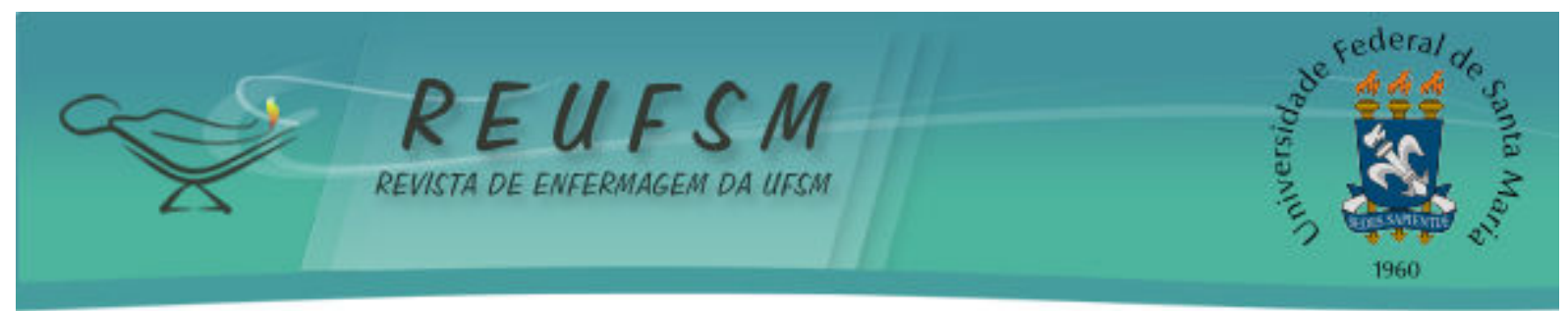

"tarefa" que, neste caso, se apresenta para as mulheres e seus familiares por meio da gestação - a vivência da parentalidade e o nascimento de uma nova família. ${ }^{4}$

Com base no referencial de grupos operativos proposto por Enrique Pichon-Rivière ${ }^{6}$, professores e discentes da área de saúde da Universidade Federal de Santa Maria (UFSM) Campus de Palmeira das Missões/RS, mantêm desde 2010, atividades de extensão universitária que congregam gestantes e familiares na forma de grupo operativo. A experiência se intitula: "Atividade grupal operativa com gestantes e familiares: interlocução de saberes no Campus Universitário da UFSM/Campus de Palmeira das Missões/RS”.

Da atuação nesse projeto surgiu a motivação e o interesse pelo objeto deste estudo, que se sintetiza na seguinte questão de pesquisa: Quais as motivações e repercussões para mulheres-mães e familiares relativas à participação em grupo operativo de gestantes? A partir dessa questão, esta pesquisa tem como objetivos: Conhecer as motivações de mulheres-mães e familiares para a participação em grupo operativo de gestantes; e identificar a repercussão de sua participação nessa atividade.

\section{MÉTODO}

O estudo, do tipo descritivo com abordagem qualitativa, foi realizado em Palmeira das Missões/RS e teve como foco o projeto de extensão universitária "Atividade grupal operativa com gestantes: interlocução de saberes no Campus Universitário da UFSM/ Palmeira das Missões/RS", cujos encontros ocorreram junto ao ambiente físico do Centro de Defesa dos Direitos da Criança e do Adolescente de Palmeira das Missões/RS (CEDEDICA).

0 grupo de gestantes possui caráter interdisciplinar e interinstitucional. Essa caracterização se justifica por reunir dois cursos da saúde (Enfermagem e Nutrição) e por formar parceria entre o Departamento de Ciências da Saúde da UFSM/Campus de Palmeira das Missões, a Secretaria Municipal de Saúde (SMS) e o CEDEDICA de Palmeira das Missões/RS. Seu objetivo principal é proporcionar às gestantes e familiares um espaço de discussão e de expressão das vivências relativas à gravidez.

A experiência se articula em dois momentos distintos. Um deles, mencionado como Momento I, diz respeito à edição do grupo de gestantes e familiares, um em cada semestre letivo. 0 grupo pode contar com até dezesseis integrantes, número limitado em virtude de um dos referenciais teóricos adotados - de grupos operativos - criado pelo psicanalista Enrique Pichón-Riviére. ${ }^{6}$ No entanto, a média de participantes nos grupos é de aproximadamente cinco pessoas.

Cada grupo de gestantes/familiares se encontra semanalmente, totalizando seis encontros que tem duração aproximada de duas horas cada um ao longo de um mês e meio de cada semestre letivo. As atividades são coordenadas pelos estudantes e professores do curso de enfermagem e nutrição, onde são abordadas temáticas referentes à gestação, parto, pós-parto, parentalidade, entre outras desta natureza. A troca de experiências e vivências é motivada pelo uso de técnicas de animação grupal, leituras reflexivas e dramatizações. Há um esforço para que as relações sejam as mais dialógicas possíveis, de modo a favorecer a reflexão crítico-reflexiva de todos os participantes, visto que as atividades se ancoram também na proposta educativa de Paulo Freire. ${ }^{7}$

0 outro momento dessa experiência (Momento II) refere-se aos encontros entre professores e estudantes, os quais planejam as atividades e avaliam cada encontro do Momento I, estudam sobre a dinâmica grupal e se instrumentalizam a respeito das temáticas já mencionadas.

A pesquisa se desenvolveu apenas com as duas primeiras edições do projeto - no qual foram considerados todos os ex-participantes - pois a terceira edição, no momento da pesquisa, estava em andamento. Cada edição, realizada no ano de 2010, teve a 


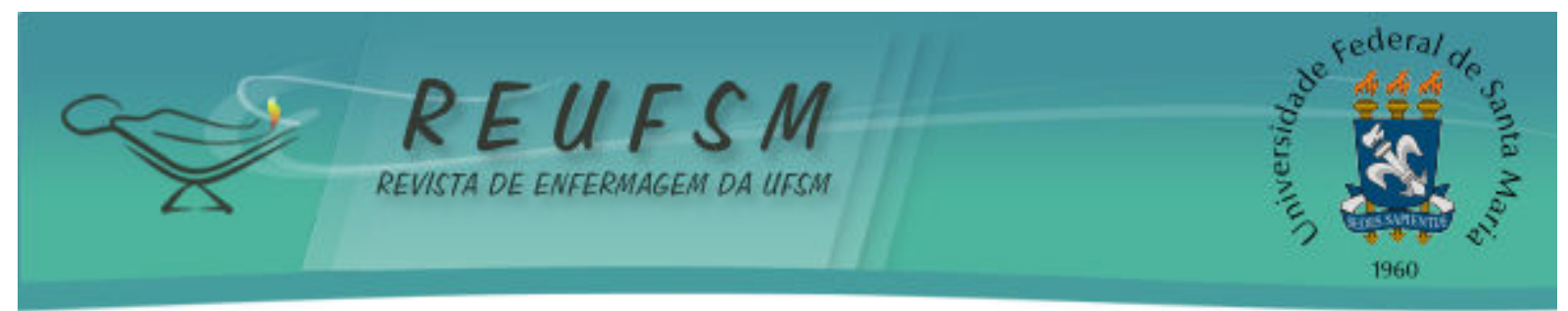

participação de oito pessoas - mulheres-mães e parceiros destas - além da equipe multiprofissional. Participaram da pesquisa seis gestantes, destas, três primigestas e três secundigestas e dois companheiros das mesmas, totalizando oito sujeitos.

Os ex-participantes foram convidados, aproximadamente um ano depois da primeira edição e meio ano da segunda. A procura de cada participante foi feita por contato telefônico, após busca na "ficha da gestante", documento criado pela coordenação da atividade que possui os dados cadastrados. Todas as entrevistas foram realizadas na residência dos sujeitos da pesquisa, após agendamento prévio. As informações foram coletadas por meio de entrevista gravada, nos meses de maio e junho de 2011. Para preservar a identidade dos participantes da pesquisa, ao final das unidades de registro, os mesmos foram identificados pela letra ' $S$ ', inicial de sujeito, seguida dos números de um a oito.

Os dados foram coletados por meio de entrevista semiestruturada, norteada pelas seguintes questões: Por quais motivos você procurou o grupo de gestantes e quais as repercussões dessa atividade em sua vida após o término dos encontros? As informações foram analisadas conforme a análise temática ${ }^{8}$, cuja operacionalidade sintetiza-se em três etapas: pré-análise, exploração do material e interpretação dos resultados. Na primeira etapa, tomou-se contato como o material produzido, por meio de leitura exaustiva, para uma impregnação das informações nele contidas; na exploração, realizou-se a categorização dos dados, quando se realizaram recortes no texto e as unidades de registro agrupadas a partir de suas afinidades temáticas; por fim, na fase de interpretação, buscouse a compreensão e interpretação dos dados à luz do referencial dos grupos operativos de Enrique Pichón-Rivière ${ }^{6}$ e da educação libertadora de Paulo Freire. ${ }^{8}$

Salienta-se ainda que houve a assinatura de um termo de consentimento, livre e informado por parte dos sujeitos investigados, conforme prevê a Resolução 466/2012 ${ }^{9}$ do Conselho Nacional de Saúde. O projeto foi aprovado pelo Comitê de Ética em Pesquisa da UFSM, em janeiro de 2011, com o seguinte número do processo 23081.007767/2011-73.

\section{RESULTADOS E DISCUSSÃO}

Tendo como ponto de partida a pergunta norteadora da pesquisa, referente às motivações e repercussões para mulheres-mães e familiares relacionadas à participação em um grupo operativo com gestantes, procurou-se apreender, nas falas dos sujeitos, as ideias que pudessem estar associadas à temática em estudo e agrupá-las em categorias, de acordo com a similaridade das informações. Dessa forma, emergiram três categorias, quais sejam: Mãe de primeira viagem: a gente não tem noção das coisas, Novos aprendizados referentes à gestação, amamentação e cuidados com o bebê e Da troca de experiências à construção de laços de amizade, as quais serão descritas a seguir.

\section{Mãe de primeira viagem: a gente não tem noção das coisas}

Com relação aos motivos que levaram as/os participantes a procurarem o grupo operativo de gestantes e familiares, a falta de experiência das "mães de primeira viagem" ou primigestas, foi o eixo norteador dessa busca, como indicam os excertos a seguir:

Como eu sou mãe de primeira viagem, eu não sabia nada ainda. (S3)

O motivo que me levou a participar foi justamente por ser o primeiro bebê, sou inexperiente. (S1)

Percebe-se, nesses depoimentos, a preocupação dessas mulheres-mães quanto a 


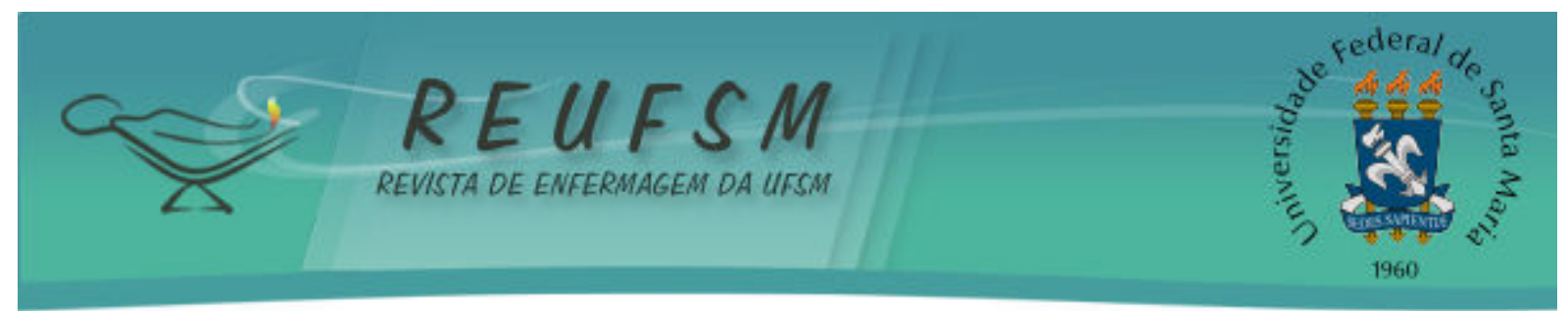

pouca experiência relativa à maternidade e suas demandas, motivo pelo qual buscaram informações a partir da participação no grupo. Também, foi percebida, pelas colaboradoras do estudo, como uma estratégia de preparação para a maternidade, visando à prestação de cuidados adequados aos seus filhos.

Problemas vivenciados por puérperas ante as demandas da maternidade também foram evidenciadas em estudo ${ }^{10}$, que objetivou relatar o destaque conferido por profissionais de Equipes de Saúde da Família (ESFs) ao puerpério na adolescência, período no qual as mulheres estão vulneráveis, quando há referência de que não é a idade da mulher que resulta dificuldades no puerpério. Tais questões são inerentes à necessidade de adaptação de todas as mães às responsabilidades relativas à maternidade.

Nesta lógica, foi possível perceber que as mulheres-mães se sentem inexperientes para o cuidado com o bebê, dada à singularidade do processo de nascimento. Da mesma forma, a necessidade de buscar informações sobre as questões relativas à gravidez, parto, puerpério e cuidados com o bebê também foi comum às participantes que já haviam vivenciado a maternidade anteriormente, como indica o relato a seguir:

A gente não tem noção das coisas, tu nunca sabe tudo, sempre tu aprende alguma coisa. (S4)

Em estudos ${ }^{11-12}$ sobre o processo educativo com gestantes e familiares é mencionado que as gestantes buscam o grupo para ampliar saberes, compreender as transformações ocorridas na gravidez e parto, os cuidados consigo e com o bebê em todo o processo. A troca de experiências e vivências sobre temas de interesse comum entre os participantes, a exemplo de práticas de cuidado com o recém-nascido, parece possibilitar a identificação entre eles, o que os vincula à tarefa grupal, que, em verdade, diz respeito à adaptação ativa aos papéis inerentes à parentalidade.

Destaca-se que essa adaptação não significa a aceitação passiva de regras sobre como cuidar de si e/ou do filho que está por vir. Diz respeito à possibilidade de "pensar" acerca das informações que recebem no grupo e, a partir dessa postura crítico-reflexiva, perceber quais recursos possuem para lidar com tais orientações. ${ }^{9,13-15}$

A proposição de grupos do tipo operativo, em consonância com o referencial teóricometodológico nortearam as atividades dos sujeitos do estudo. Nesse sentido, houve uma preocupação em superar o enfoque recorrente das práticas educativas, pautadas na centralidade da transmissão de informações e na prescrição de comportamentos saudáveis. Dessa forma, as trocas de informações foram direcionadas ao preparo adequado da gestante para o desempenho de seu papel materno, com foco final na saúde do bebê, da mulher-mãe e de sua família.

A adoção de abordagens de natureza emancipatória, como as que orientaram o grupo operativo, favorece a mobilização de recursos individuais e coletivos direcionados a modos de viver mais saudáveis, focados no empoderamento feminino, fortalecimento da autonomia e cidadania e maior possibilidade de escolha dos sujeitos quanto às ofertas de cuidado à saúde. ${ }^{10}$

\section{Novos aprendizados referentes à gestação, amamentação e cuidados com o bebê}

O processo de análise dos dados da pesquisa revelou que os participantes incorporaram em seu cotidiano vários saberes que circularam no grupo operativo, os quais, em alguma medida, contribuíram para um cuidado diferenciado ao bebê, ou seja, distinto do realizado com o primeiro filho. Como exemplificou o companheiro de uma das participantes, a troca de saberes e de experiências no grupo favoreceu que sua esposa amamentasse efetivamente seu filho:

Sobre o mamá, meu primeiro filho não mamou, a gente não teve 


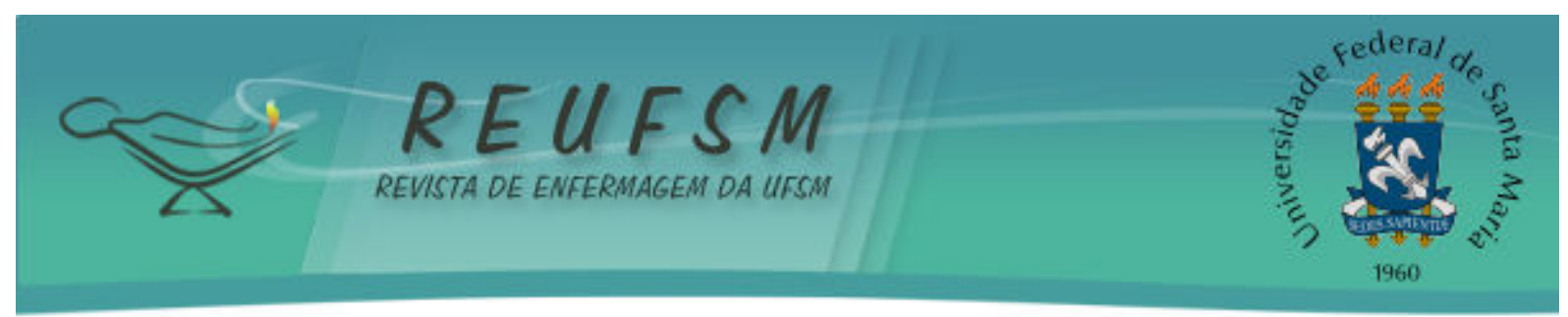

esse aprendizado de como fazer para ele mamar, para sair o leite $e$, daí no grupo, a [enfermeira] explicou bem direitinho como fazer, foi feito e ela tinha bastante leite. (S8)

Por meio desse depoimento percebe-se que o grupo operativo de gestantes possibilitou novos aprendizados, superação de dificuldades e motivação para que esse casal vivenciasse a prática do aleitamento materno. Ainda, quanto às dificuldades superadas a partir da interação grupal, destaca-se que o grupo também ajuda a aproximar e concretizar situações distantes como o pós-parto, tais como, os cuidados com a mãe e com o recém-nascido e a prática do aleitamento. ${ }^{11}$

No processo grupal, as informações foram sendo compartilhadas mediante a troca de experiências e vivências entre os participantes, o que se deu de forma horizontalizada, pois todos foram sujeitos ativos na medida em que tanto ensinaram como aprenderam novos saberes. ${ }^{7,15}$

Na parte do umbigo no primeiro filho eu usava faixa. Desse aqui [segundo filho] já não fiz, eu pensei e tratei bem do jeito que elas me ensinaram, assim sarou bem curadinho. (S5)

No banho do nenê antes eu pegava (risos) e dava o banho no corpinho inteiro. Ali [no grupo de gestantes] elas me disseram que poderia ser diferente! Tem até a diferença porque é no inverno, então eu pegava lavava a cabecinha e ficava bem ai, depois tirava a roupa e lavava e não se gelava muito. (S6)

O grupo fornece subsídios para que os participantes reflitam sobre as diversas possibilidades, condutas e ofertas de cuidado implicadas no processo de nascimento, assumindo, desta forma, o protagonismo deste processo. ${ }^{11}$

Outro aspecto, diz respeito à repercussão dessa participação na vivência da gestação com mais segurança. Para os participantes, o grupo trouxe segurança nos cuidados com o bebê, o que ocorreu, a partir do aprendizado mediado pelas atividades realizadas no grupo, como por exemplo, a construção do corpo e as modificações gravídicas; demonstração do parto normal com a utilização de bonecos; exercícios para aliviar a dor na hora do parto; o colar da alimentação - alimentos para o bebê após seis meses - entre outras, as quais foram destacadas em alguns depoimentos:

Aprendi um monte de coisas que eu não sabia, os cuidados com o bebê, aumentou a minha segurança pra lidar com o bebê. (S1)

Do umbigo dela [filha] também quem me ensinou a cuidar foi elas [enfermeiras, nutricionistas e acadêmicas], eu não sabia nada, daí eu aproveitava a dica delas pra mim fazer com ela. Banho, temperatura de água elas me ensinaram, da alimentação até hoje eu cuido, a alimentação dela foi elas que me ensinaram, me deram dicas também de como fazer os alimentos pra ela. (S3)

No campo da saúde, as práticas educativas se configuram como importante elemento para a promoção da saúde, levando ao desenvolvimento de um pensar mais críticoreflexivo, favorecendo a produção da autonomia dos sujeitos. Ações dessa natureza possibilitam a produção de um saber que seja capaz de propor mudanças, fazendo com que o indivíduo decida sobre as questões relativas aos cuidados com sua saúde e/ou de sua família, 


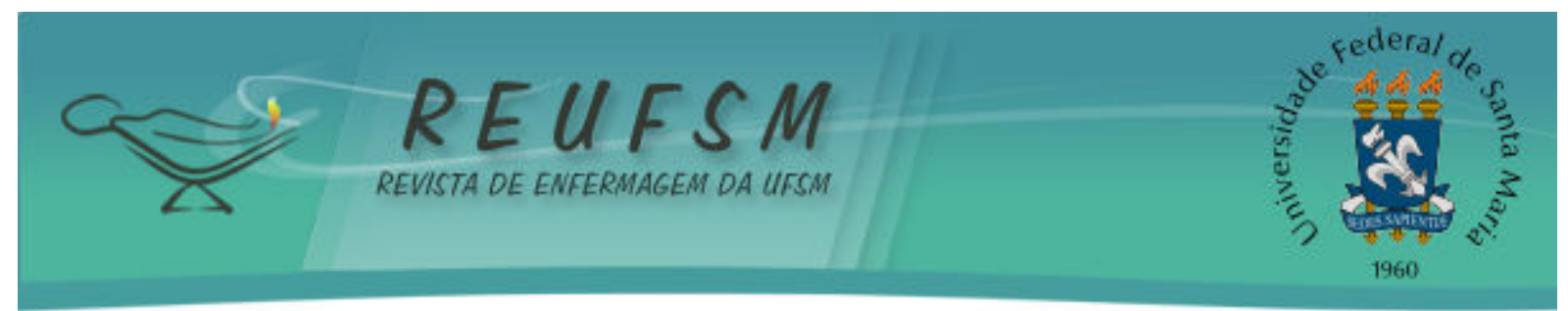

através de um contexto dialógico em que a horizontalidade das inter-relações possibilite a troca de saberes entre os participantes, como aconteceu na experiência ora relatada. ${ }^{7,15}$

Assim, percebe-se que a proposição da atividade grupal foi exitosa na medida em que proporcionou, aos participantes, espaço de discussão e de expressão das vivências relativas à gravidez, bem como a mobilização de recursos individuais e coletivos implicados no processo de adaptação a essa nova situação de vida. Esses achados corroboram resultados de outros estudos da mesma natureza, quando apontam que a participação em grupo de gestantes propicia aos seus integrantes segurança, esclarece dúvidas e orienta sobre formas de como cuidar de si e do filho. ${ }^{11-13}$

Além disso, identifica-se que a participação no grupo operativo com gestantes favoreceu, a uma dessas mulheres, a realização de uma aspiração antiga que era amamentar.

O que eu mais queria, o meu sonho era poder dar de mamar para ele [segundo filho] no peito. Daí elas me ensinaram tudo o que eu tinha que fazer e que era pra insistir. Daí, dessa vez foi fácil! Dessa vez eu consegui. Fiz bem do jeito que elas falaram e dou de mamar até agora. (S5)

Nesta fala, fica evidente que houve a resolução de antigos conflitos, que geravam insatisfação ao sujeito de pesquisa. Houve mudança de atitude e, consequentemente, a concretização de um sonho, que era amamentar seu filho. Dessa forma, a participação no grupo contribui para operar-se a produção de novos saberes e atitudes, os quais passam a fazer sentido para as pessoas e, por isso, contribuem à adaptação ativa à realidade vivida. ${ }^{14}$

No grupo operativo, as pessoas passam de situação fixas e estereotipadas (dilemáticas) para outras de natureza flexível, que permitem questionamentos (dialéticas). ${ }^{14}$ Assim, por meio da operatividade do grupo, os participantes, a exemplo das mulheres-mães deste estudo, passam da imobilidade e resistência ao movimento e à mudança.

0 grupo favoreceu a mudança de alguns hábitos alimentares, o que indica que a atividade teve como repercussão efeitos terapêuticos ${ }^{14,16}$, como pode ser apreendido no excerto de fala a seguir

Eu aprendi a tomar água depois [do grupo], bastante água todos os dias que eu não tomava muita água. Parei com o salame agora por causa da cólica e comecei também a comer bastante coisa que eu não comia, tipo verdura, essas coisas, saladas que foi a nutricionista que me orientou, aí eu sempre lembrava dela: vou comer alface! (S2)

Os sujeitos reconheceram e valorizaram a importância da presença da equipe multiprofissional, pois suas experiências contribuíram positivamente para novos aprendizados referentes à gestação.

Ela me falou que ia ter as enfermeiras e tudo [outros profissionais] pra me explicar. Eu pensei que seria interessante, porque qualquer dúvida que eu tivesse poderia tirar. (S2)

A operatividade no campo grupal, a partir de uma experiência multiprofissional, favorece a problematização de questões emergentes que, muitas vezes, não são do núcleo de saber e competência de um profissional em específico. Tal situação é corroborada por estudo que trata da interdisciplinaridade em atividades de promoção à saúde de natureza 


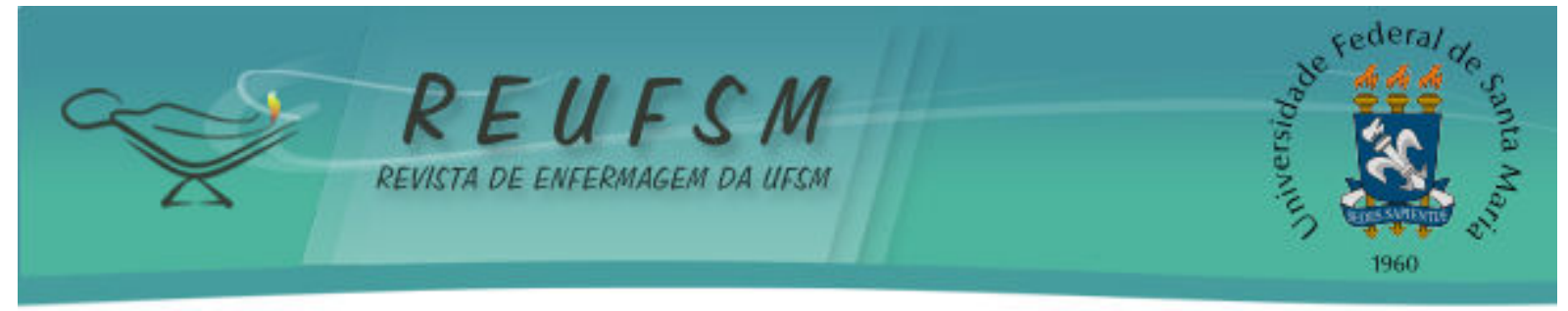

grupal operativa. ${ }^{13}$

A presença da equipe multiprofissional parece ter agregado ao grupo de gestantes uma atenção mais humanizada e integral referente à promoção da saúde dos participantes. Cada profissão possui um núcleo específico de saberes que, ao se aproximar e interagir com o núcleo de outra área profissional, favorece a conjugação de diferentes olhares, os quais, na medida em que se complementam, conferem mais consistência às ações no campo da promoção da saúde.

\section{Da troca de experiências à construção de laços de amizade}

Durante os encontros grupais, as mulheres-mães e seus familiares relataram que, além do aprendizado com a equipe multiprofissional, houve também, a troca de experiências com os demais participantes. Um importante destaque positivo, reconhecido pelos sujeitos do estudo, foi a presença de pessoas que já vivenciaram o processo gestacional, contribuindo para minimizar preocupações e anseios de quem o experienciava pela primeira vez.

Estudos ${ }^{15-17}$ sobre grupos, fundamentados no referencial Pichoniano ${ }^{6}$ e/ou de Paulo Freire $^{7}$, ainda que não específicos ao período gestacional, destacam que a participação e interação grupal, na medida em que possibilita a troca de informações, também auxilia no esclarecimento de dúvidas que são comuns. Assim, apesar da singularidade das vivências de cada um, os saberes são compartilhados, favorecendo a troca de experiências e a produção de novos saberes, ancorados numa perspectiva crítico-reflexiva, como indicam os depoimentos a seguir.

A gente trocou experiências. Como elas já tinham os filhos primeiro do que nós, daí já aprendemos sobre isso. Muito interessante. (S8)

Foi bem legal interagir com elas que já tinham filhos. Elas falavam das coisas que aconteciam com elas, interagir com outras grávidas que elas também sentiam as mesmas coisas que você. (S3)

A oportunidade de trocar saberes e vivências sobre a gestação, de expressar sentimentos, medos e dúvidas, conhecer experiências e refletir sobre situações semelhantes às suas possibilita a construção coletiva do conhecimento. Além disso, fortalece o entendimento pessoal, a superação de limitações e novas oportunidades para entender o processo do nascimento. ${ }^{11}$

Outro aspecto que emergiu foi à formação de laços de amizade entre os participantes do grupo de gestantes. 0 convívio com outras pessoas, por um determinado período de tempo neste mesmo processo e, até mesmo, a relação dos participantes com a equipe multiprofissional proporcionou interações formando novas redes sociais.

\section{Ali dentro [no grupo] a gente fez uma amizade! (S6)}

Foi muito bom assim, conhecer mais outras pessoas $e$ mais as professoras também. (S5)

Neste sentido, as interações mantidas no grupo operativo de gestantes estimulam o apoio mútuo e a solidariedade entre os indivíduos, além do fortalecimento da cidadania e inclusão social, o que é corroborado em outro estudo de natureza semelhante a esse ${ }^{11}$. 


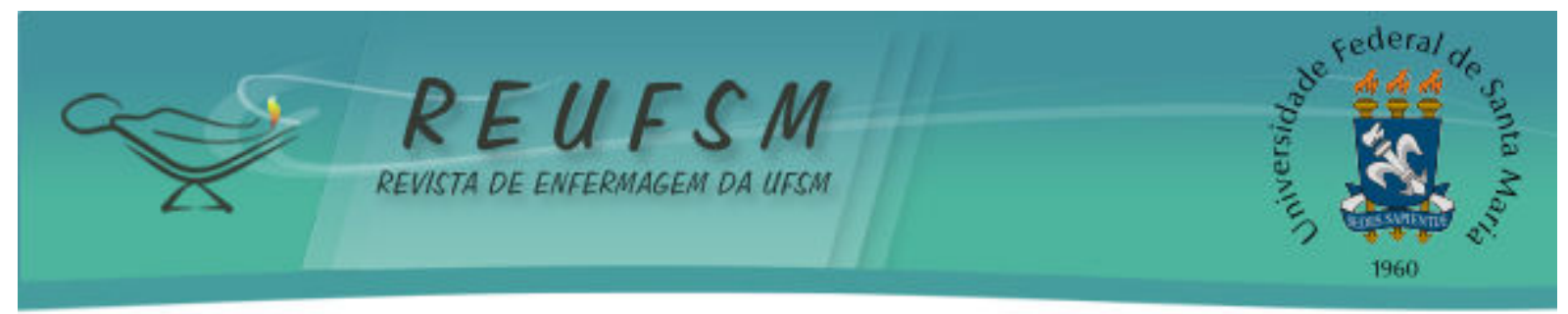

\section{CONSIDERAÇÕES FINAIS}

No contexto do estudo, a necessidade de mais informações relativas ao período gestacional e cuidados com o bebê motivaram a busca dos participantes pela atividade grupal operativa com gestantes e familiares.

Além da procura de maior segurança com os cuidados com o bebê, os resultados deste estudo mostraram que o grupo se constituiu como um espaço de reflexão, de escuta, de diálogo, de troca de saberes e experiências sobre as demandas da maternidade e cuidados de saúde no período gravídico-puerperal.

A interação grupal resultou na formação de laços de amizade entre os participantes do grupo operativo com a equipe multiprofissional e o convívio com pessoas diferentes de sua comunidade, outras mulheres-mães e familiares com quem não matinham contato no dia-a-dia, oportunizando a ampliação das relações interpessoais e a construção de novas redes sociais.

A presença de equipe multiprofissional e a dialogicidade da prática educativa constituída pela troca de informações entre os participantes foram importantes no processo grupal, pois favoreceram a humanização e a integralidade da atenção, dispositivos qualificadores do processo de promoção da saúde.

Este estudo contribui para a construção de conhecimentos relativos a grupos operativos como estratégia educativa, terapêutica e promotora da saúde de mulheres e familiares que vivenciam o processo de nascimento. Sinaliza também, para a pertinência da oferta de mais ações de natureza semelhante a estas às gestantes e familiares.

Vale ressaltar que além das contribuições deste estudo, que uma das limitações diz respeito ao seu caráter local. Destaca-se assim, a necessidade do desenvolvimento de investigações com populações de outros cenários e com outros desenhos metodológicos para a sua ampliação.

\section{REFERÊNCIAS}

1. Cabral FB, Hirt LM, Van der Sand ICP. Atendimento pré-natal na ótica de puérperas: da medicalização à fragmentação do cuidado. Rev Esc Enferm USP [Internet]. 2013 [acesso em 2013 mar 13];47(2):281-7. Disponível em: http://www.scielo.br/pdf/reeusp/v47n2/02.pdf.

2. Carneiro MS, Teixeira E, Silva SED, Carvalho LR, Silva BAC, Silva LFL. Dimensões da saúde materna na perspectiva das representações sociais. Rev Min Enferm [Internet]. 2013 abr/jun [acesso em 2014 jan 20];17(2):446-53. Disponível em: http://www.reme.org.br/artigo/detalhes/662.

3. Mota IIS, Moreira MA. Assistência pré-natal: conhecimentos de gestantes atendidas em uma maternidade pública da Bahia. J Health Sci Inst [Internet]. 2013 [acesso 2014 jan 20];31(1):43-7. Disponível em: http://www.unip.br/comunicacao/publicacoes/ics/edicoes/2013/01_janmar/V31_n1_2013_p43a47.pdf.

4. Zimermann DE, Osório LC. Como trabalhamos com grupos. Porto Alegre: Artes Médicas; 1997.

5. Afonso MLM. Grupos: o que são e como se organizam. In: Afonso MLM, organizadora. Oficinas em dinâmica de grupo na área da saúde. $2^{a}$ ed. São Paulo: Casa do Psicólogo; 2010. Texto 1, p. 27-58.

6. Pichón-Rivière E. Psicologia grupal. 8a ed. Rio de Janeiro: Martins Fontes; 2009. 


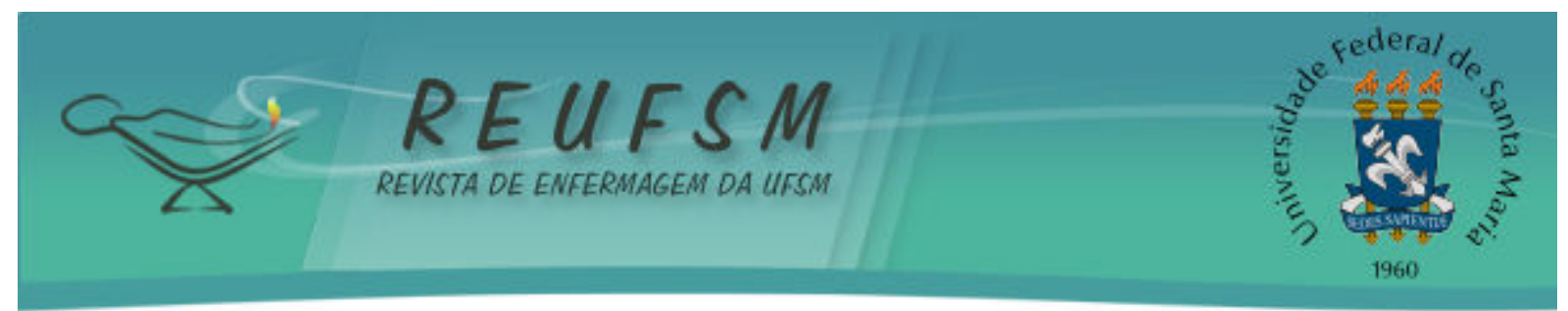

7. Freire P. Conscientização: teoria e prática da libertação: uma introdução ao pensamento de Paulo Freire. $3^{a}$ ed. São Paulo: Centauro; 2008.

8. Minayo MCS. O desafio do conhecimento: pesquisa qualitativa em saúde. $10^{a}$ ed. São Paulo: Hucitec; 2007.

9. Brasil. Ministério da Saúde. Conselho Nacional de Saúde. Resolução $n^{\circ}$ 466, de 12 de dezembro de 2012. Aprova diretrizes e normas regulamentadoras de pesquisa envolvendo seres humanos. Brasil: Conselho Nacional de Saúde; 2012.

10. Cabral FB, Oliveira DLLC de. Vulnerabilidade de puérperas na visão de Equipes de Saúde da Família: ênfase em aspectos geracionais e adolescência. Rev Esc Enferm USP [Internet]. 2010 [acesso em 2013 mar 10];44(2):368-75. Disponível em: http://www.scielo.br/pdf/reeusp/v44n2/18.pdf.

11. Zampieri MFM, Gregório VRP, Custódio ZAO, Regis MI, Brasil C. Processo educativo com gestantes e casais grávidos: possibilidade para transformação e reflexão da realidade. Texto \& Contexto Enferm [Internet]. 2010 out-dez [acesso em 2013 mar 9];19(4):719-27. Disponível em: http://www.scielo.br/pdf/tce/v19n4/15.pdf.

12. Maron LC, Lagomarsino BS, Brizola NA, Van der Sand ICP, Cabral FB. Atividade grupal operativa com gestantes e familiares: um relato de experiência. Rev Contexto \& Saúde (Ijuí) [Internet]. 2011 jan/jun [acesso 2014 jan 24];10(20):161-8. Disponível em: https://www.revistas.unijui.edu.br/index.php/contextoesaude/article/view/1514/1275.

13. Van der Sand ICP, Campos IFA, Dreher DZ, Rios KR. Metodologia de atenção à gestante e família: relato de experiência com Grupo operativo. Rev Enferm UFSM [Internet]. 2011 set/dez [acesso em 2013 fev 25];1(3):497-505. Disponível em: http://cascavel.ufsm.br/revistas/ojs-2.2.2/index.php/reufsm/article/view/2918.

14. Souza AC, Colomé ICS, Costa LED, Oliveira DLLC. A educação em saúde com grupos na comunidade: uma estratégia facilitadora da promoção da saúde. Rev Gaúcha Enferm [Internet]. 2005 [acesso em 2013 mar 13];26(2):147-53. Disponível em: http://www.lume.ufrgs.br/bitstream/handle/10183/23558/000560718.pdf?...1.

15. Soares SM, Ferraz AF. Grupos operativos de aprendizagem nos serviços de saúde. Esc Anna Nery Rev Enferm [Internet]. 2007 mar [acesso 2014 jan 24];11(1):52-7. Disponível em: http://www.scielo.br/pdf/ean/v11n1/v11n1a07.pdf.

16. Almeida SP, Soares SM. Aprendizagem em grupo operativo de diabetes: uma abordagem etnográfica. Ciênc Saúde Coletiva [Internet]. 2010 [acesso em 2013 mar 13];15 Supl 1:1123-32. Disponível em: http://www.scielo.br/scielo.php?pid=S1413$81232010000700020 \&$ script=sci_arttext.

17. Favoreto CAO, Cabral CC. Narrativas sobre o processo saúde-doença: experiências em grupos operativos de educação em saúde. Interface Comun Saúde Educ [Internet]. 2009 jan/mar [acesso em 2013 mar 9];13(28):7-18. Disponível em: http://www.scielo.br/scielo.php?script=sci_arttext\&pid=S1414-32832009000100002.

Data de recebimento: $01 / 10 / 2013$

Data de aceite: 09/07/2014

Contato com autor responsável: Luana Carine Maron

Endereço: Rua Dr Francisco Timm, n³68, Centro, Santa Rosa,RS. Brasil.

Email: luana.maron12@hotmail.com 